\title{
ОЦЕНКА УРОВНЯ УСТОЙЧИВОГО ЭКОНОМИЧЕСКОГО РАЗВИТИЯ И ЭКОНОМИЧЕСКАЯ БЕЗОПАСНОСТЬ ОТРАСЛЕЙ МИНЕРАЛЬНО- СЫРЬЕВОГО КОМПЛЕКСА РОССИИ
}

\author{
(C) 2018 Мясоедов Сергей Александрович \\ доктор экономических наук, доцент \\ профессор кафедры «Бизнес процессов и экономической безопасности» \\ Академия маркетинга и социально-информационных технологий - ИМСИТ \\ 350010, г. Краснодар, ул. Зиповская, 5 \\ E-mail:myasoedov8@mail.ru
}

Продвижение идей устойчивого развития требует постоянного мониторинга индикаторов устойчивого развития. Основная проблема вызвана отсутствием универсальных показателей, принятых общественностью и специалистами. Под лозунгами сохранения природы, ресурсов для будущих поколений промышленные развитые государства оправдывают обоснованность разработки месторождений стратегических полезных ископаемых только отечественными ТНК. В результате, идеи устойчивого развития используются в качестве тактических приёмов в рамках ведения сетецентрических войн по обладанию стратегическими полезными ископаемыми. Для защиты национальных интересов Российская Федерация необходимо определить и законодательно закрепить критические значения показателей по присутствию иностранного транснационального капитала во владении и управлении ключевыми организациями, занимающихся добычей и переработкой невозобновляемых полезных ископаемых на территории России. Оценивать уровень достижения устойчивого развития минерального сырьевого комплекса нашей страны возможно только с учётом национальных интересов.

Ключевые слова: устойчивое развитие, показатели оценки устойчивого развития экономики, сетецентрическая война, показатели обеспечения устойчивого развитии минерально-сырьевого комплекса России.

25 сентября 2018 года прошёл Саммит по устойчивому развитию в штаб-квартире $\mathrm{OOH}$ в рамках 70-й сессии Генеральной Ассамблеи. Для Российской Федерации приоритетом в рамках глобального устойчивого развития является борьба с бедностью [1]. Достоверность заявленного направления подтверждается содержанием главы VI «Основные показатели состояния национальной безопасности» Стратегии национальной безопасности Российской Федерации (Указ Президента Российской Федерации от 31 декабря 2015 года N683). В указанной главе пункт 115, из 10 основных показателей, необходимых для оценки состояния национальной безопасности, пять позволяют оценить эффективность проводимой политики по заявленному направлению обеспечения процессов устойчивого развития в экономике Российской Федерации, а именно: децильный коэффициент (соотношение доходов 10 процентов наиболее обеспеченного населения и 10 процентов наименее обеспеченного населения); уровень инфляции; уровень безра- ботицы; валовой внутренний продукт на душу населения; ожидаемая продолжительность жизни [3].

Первоначально при формировании основ устойчивого развития предполагалось, что оценка уровня устойчивого развития определяется по четырём основным направлениям: экологические, институциональные, социальные, экономические.

Основными проблемами при разработке групп диагностических показателей (индикаторов) устойчивого развития можно назвать:

- отбор показателей и формирование списка показателей;

- создания возможностей для детализации имеющихся показателей в разрезе подсистем оцениваемых субъектов;

- определение объективной величины показателя, постоянный мониторинг и корректировка количественного значения показателя;

- выявление и определение структурного веса показателя в группе и группы в системе по- 
казателей.

В международной практике при разработке показателей оценки устойчивого развития применяются подходы:

- построение системы индикаторов по направлениям;

- построение интегрального индикатора устойчивости развития.

Разработка системы показателей предусматривает алгоритм использования каждого показателя по системе:

а) проблема - индикатор;

б) воздействие - состояние - реакция (давление - состояние - реакция);

в) цель - задачи - индикаторы и другие.

Методология измерения процессов устойчивого развития находится в стадии становления, по причине многокомпонентности направлений развития, динамичности ситуаций, сложности выработки универсальных либо унифицированных показателей. При этом разработка индикаторов (показателей) требует существенного объёма информации, знание сути ситуаций и правильных причинно-следственных связей.

До сих пор отсутствуют однозначные в оценке, унифицированные показатели (индикаторы) устойчивого развития экономики.

Наиболее часто встречаемые показатели в научно-практической литературе, получившие практическое применение в оценке процессов устойчивого развития включают:

1. Интегральные показатели: Adjusted net savings, Environmental Health Damage, Environmentally adjusted product, Human development index, Living Planet Index, The Ecological Footprint и т.п.

2. Экологические индексы: EPI, Environmental Burden of Disease, Water Quality Index, Water Stress Index, Water Scarcity Index, Conservation Risk Index, Biome Protection, Critical Habitat Protection, Growing Stock Change, Marine Trophic Index, Trawling Intensity, Agricultural Water Intensity идругие.

3. Институциональные интегральные показатели: GCI - Growth Competitiveness Index, Business Competitiveness Index, Rule of Law Score, Government Effectiveness, Voice and Accountability, Law and Order, Graft (corruption), Corruption Perceptions Index, Political stability and lack of violence, ECA - Europe and Central Asia Index, CPIA - Country Policy and Institutional Assessment Index, WCY - The World Competitiveness
Yearbook, ICRG - International Country Risk Guide, Transparency International и другие.

4. Социальные показатели: Community Assets, Community Leadership and Pride, Individual Well-being, Urban Economy, Urban Environment, GEM - Gender Empowerment Measure, GDI Gender Related Development Index, HDI - Human Development Index, Income-Distribution Adjusted Index, Human Poverty Index 1, 2, GID, WHO QOL, Human Well-Being Index (HWI), HealthRelated Quality of Life - HR QOL, Johnston's QOL Index - JQOLY, Comprehensive Quality of Life Scale - ComQol, PQLI, CQLI, Netherlands Living Conditions Index - NLCI, Index of Economic WellBeing - IEWB, American Demographics Index of Well-Being - ADIWB, Genuine Progress Index GPI, Index of Social Progress - ISP, Index of Human Progress, Happy Life-Expectancy Scale - HLE, HKSDI - Hong Kong Sustainable Development Index, International Living Index - ILI, North American Social Report - NASR, Index of Social Health - ISH, Consumer Confidence Index - CCI и другие.

На саммите БРИКС в 2017 году Президент России В.В. Путин отметил, что «...помощь в реализации Целей устойчивого развития не должна увязываться с какими-либо политическими требованиями и условиями...» [2].

Получили практическое применение схемы захвата мировыми транснациональными корпорациями (ТНК) месторождений стратегического сырья в странах третьего мира под эгидой соблюдения экологических норм (в рамках обеспечения основ устойчивого развития цивилизации).

Идея устойчивого развития цивилизации и экономики активно используется как инструментарий сетецентрических войн.

Война нового поколения сопряжена, прежде всего, с пониманием того, что война ведётся не только во время проведения войсковых операций, с использованием боевой техники и вооружений, но и во время между боевыми действиями продолжительностью в годы и десятилетия. Поэтому все экономические, социальные, информационные, политические акции классифицируются в боевые операции.

Сетецентрическая война (сетевая война) - скоординированный комплекс действий, обеспечивающих достижение информационного превосходства, за счёт изменения ценностных, нравственных, социальных, экономических, 
национальных, образовательных стандартов и ориентиров окружающего мира.

Ввод войск необязателен при новой (сетевой) войне, если бизнес структуры противника либо иные агенты противника получают легальный доступ к необходимым им природным, материальным, интеллектуальным ресурсам за счёт проведения эффективных политических акций, экономических мероприятий и т.д.

Цель сетевой войны - установление контроля над всеми участниками боевых действий (противник, союзник, а также нейтральный субъект) в мирное и военное время и постоянное формирование среды для манипулирования ими и всеми ресурсами, им принадлежащим.

Наша страна обладает богатейшими запасами полезных ископаемых, но одновременно и мощными Вооружёнными Силами, обеспечивающими паритета сил, гарантированное взаимное уничтожения. Следовательно, не войсковая фаза сетевых войн является решающей для достижения цели не военным путём.

Практика разработки месторождений стратегических полезных ископаемых в Российской Федерации связана с допуском представителей крупнейших мировых ТНК в систему менеджмента, управления, владения.

К сожалению, в России сохраняются элементы системы разработки месторождений полезных ископаемых, применяемой к государствам третьего мира, «банановым республикам».

Не сложно предугадать реакцию политиков ведущих государств мира, если бы российские бизнес структуры, стали бы владельцем или были бы допущены к разработке месторождений стратегических полезных ископаемых на территории данных государств, а в Российской Федерации это не редкость.

Война нового типа (сетевая - networkcentricwarfare) требует применение новых принципов оперативной тактики и стратегии.

Геополитическая концепция предусматривает реализацию технологии сетевых войн, суть которых обеспечить захват ресурсов другого государства и победу над противником, используя, в большинстве случаев не военные методы борьбы.

Если в прошлые века борьба велась за земное, водное и воздушное пространство, то в настоящее время довольно жёсткое противостояние наблюдается на информационном, экономическом пространстве, борьба ведётся также за со- знание людей, за возможность формировать их ценностные ориентиры.

И всё это делается только с одной целью получить беспрепятственный доступ к ресурсам государств мира и обеспечить над ними контроль.

Факты последних лет позволяют отметить ещё одну характерную особенность: для несогласных «не демократических» («проблемных») стран предусмотрен военный сценарий развития.

Государственное управление минерально-сырьевым комплексом страны вызывает целый ряд обоснованных беспокойств, например, начиная от потерь экономической выгоды для России по ряду положений соглашений о разделе продукции по нефтегазовым месторождениям, до передачи американским, английским, китайским компаниям в разработку уникальных месторождений стратегических не возобновляемых полезных ископаемых. В то время как ряд индустриально ведущих государств мира за счёт налогового механизма, таможенных пошлин резко ограничивают экспорт из своих стран рудных концентратов, металлов, минерального сырья.

Дальнейшая корректировка условий разработки по проектам с участием крупных иностранных компаний, по причине объективного изменения ряда факторов, практически не представляется возможным. Более того, процесс осуществления необходимого контроля за деятельностью подобных предприятий, постоянно ограничивается мероприятиями дипломатического и экономического давления иностранных государств на нашу страну.

Минеральные ресурсы страны отданы на откуп частному бизнесу, в том числе международному, транснациональному. При этом граждане Российской Федерации, в отличие от граждан Норвегии, Саудовской Аравии, Кувейта, Канады и других государств слабо ощущают на своём финансовом состоянии положительные аспекты такой политики освоения полезных ископаемых России.

Поэтому и наблюдается рост богатых людей нашей страны среди лиц, занятых разработкой, транспортировкой полезных ископаемых при одновременном существовании граждан страны на грани прожиточного минимума, что только увеличивает децильный коэффициент по стране и повышает уровень социальной напряжённо- 
сти. Подобные диспропорции в вышеназванных странах ликвидируют за счёт научно - обоснованного изъятия рентных доходов у недропользователей.

Незыблемыми постулатами при формировании основ устойчивого развития минерально-сырьевого комплекса России в реалиях ведения сетецентрической войны должны являться:

1. Ограничение доступа для крупных иностранных компаний к разработке месторождений полезных ископаемых, с последующим негласным запретом деятельности в сфере недропользования на территории Российской Федерации международных ТНК и ведущих недродобывающих компаний мира.

2. Привлечение ограниченного числа иностранных участников, в виде мелких венчурных компаний, не связанных с крупными иностранными добывающими компаниями и ТНК. Целью привлечения является внедрение в технологический процесс разработки месторождений полезных ископаемых передовых научно-технических разработок, методов и способов добычи и переработки полезных ископаемых на территории России.

3. Законодательно ограничить вывоз за пределы Российской Федерации не возобновляемых стратегических полезных ископаемых (золото, алюминий, титана, алмазы и т.д.), не прошедших глубокой стадии переработки.

4. Постепенное, системное закрепление и внедрение на законодательном уровне инструментов процесса «деприватизации» недродобывающих и перерабатывающих предприятий Российской Федерации (более радикальный пример - Венесуэла).

В процессе обоснования индикаторов оценки устойчивости развития минерально-сырьевого комплекса исходим из следующих требований к показателям по системе «человек - общество природа»:

- количество показателей не стабильно, их совокупность подвержена изменениям и уточнениям;

- показатели должны быть простыми в расчётах, должны содержать общеизвестные, широко признанные составляющие, содержать однозначную интерпретацию;

- в каждой группе показателей определяется ведущий индикатор, в системе доминирующая группа;

- существование возможности взаимно пе- реводимости показателей в интегральные;

- должны иметь пороговые и эталонные значения;

- унифицированы с международными показателями;

- быть объективным;

- обеспеченным теоретической научной основой;

- доступность к информации для их расчёта;

- достоверность информационной базы должна быть гарантирована официальными источниками;

- должны быть значимы для принятия решений;

- возможность оценки во временной динамики.

Разработка отраслевых индикаторов требует охвата как минимум трёх основных направлений взаимосвязей:

- экономические связи между отраслью и различными средами (социальной, институциональной средой и т.д.);

- экологические взаимосвязи между отраслью и биосферой;

- взаимосвязь по обеспечению достижения сформировавшихся положительных тенденций развития отрасли с корректировкой на экологические экстерналии.

На постоянном контроле должна находиться динамика следующих параметров устойчивого развития минерально-серьевого комплекса России:

a) пределы иностранного участия в капитале отечественных организаций недропользователей;

б) отраслевые ограничения для иностранного капитала при разработке месторождений стратегических полезных ископаемых;

в) система действий иностранных компаний, ТНК и её результативность по ограничению и снижению конкурентных возможностей отечественных организаций на мировых рынках;

г) соблюдения экологических требований при разработке месторождений полезных ископаемых;

д) эффективность привлечения и использования средств в минерально-сырьевом комплексе;

е) соблюдения технологического процесса освоения месторождения;

ё) внедрение экономических и налоговых 
инструментов, стимулирующих разработку и применение передовых и инновационных методов добычи и способов переработки сырья.

Задачи управления при обеспечении процессов устойчивого развития:

- повышение эффективности мониторинга формирования ситуации достижения устойчивости развития;

- оценка достигнутых результатов;

- анализ эффективности проводимых мероприятий, политики;

- формирование информационной основы для прогнозирования и принятия решений;

- улучшение качества управления процессами обеспечения устойчивости развития отрасли.

Исходя из выше изложенного, необходимо совершенствовать работу по формированию набора инструментов стимулирующих устойчивое развитие системы недропользования в рамках следующих направлений:

- корректировка соответствующей нормативно-правовой базы (одновременное ужесточение институциональных основ недропользования при повышении гибкости использования норм недропользования; пересмотр налоговой политики в направлении изменения налогооблагаемой базы рентных налогов и платежей и дифференциации ставок рентных налогов и платежей по горно-геологическим и географо-экономическим характеристикам месторождений);

- более детальное расширение перечня показателей, предоставляемых недропользователями в бухгалтерской (финансовой) отчётности, по направлению средств на ГГР, по привлечению заёмных средств, в том числе от иностранных инвесторов, о величине задолженности иностранным компаниям либо компаниям с иностранным участием и другие показатели, определяемые параметрами национальной безопасности;

- создание единого информационного поля между контролирующими региональными, федеральными государственными структурами;

- издание регулярного ежегодного справочника перечня основных действующих и потенциальных угроз национальной безопасности, либо в рамках экономической безопасности, с обязательной детализацией угроз в минерально-сырьевом секторе экономики;

- включение в систему подготовки кадров для государственной службы и минерально-сырьевого сектора изучение дисциплины «Экономическая безопасность», либо изучение её базовых дидактических единиц в виде факультатива;

- создать межведомственную комиссию по выявлению и нейтрализации угроз экономической безопасности в минерально-сырьевом комплексе, в обязанности которой входило бы и стратегическое планирование в данной сфере экономики;

- стимулирование создания вертикально интегрированных промышленных групп в различных недродобывающих отраслях;

- стимулирование внутреннего спроса на продукцию минерально-сырьевого комплекса в различных стадиях его передела.

Современный мир динамично меняется, одновременно изменяя формы и методы борьбы между государствами за ресурсы.

Использование идей устойчивого развития цивилизации для достижения преимуществ одними государствами над другими не приемлемо.

Поэтому все глобальные процессы обязательно должны проходить оценку по воздействию на параметры национальной, экономической безопасности нашей страны.

\section{Библиографический список}

1. https://wsdconf2018.org/ru/news/generalnaya-assambleya-oon-zapuskaet-desyatiletnij-plan-dejstvij-vodadlya-ustojchivogo-razvitiya/

2. https://iz.ru/641522/2017-09-05/putin-tceli-ustoichivogo-razvitiia-ne-dolzhny-uviazyvatsia-s-politikoi

3. Стратегия национальной безопасности Российской Федерации www.pravo.gov.ru.

4. Дроздов Ю.И., Илларионов С.И. На рубеже эпох - о современных геополитических потрясениях Москва. 2009. 208 c.

5. Дроздов Ю.И., Маркин А.Г. Наглый орёл - 2009. (Разведка и война в системе США). [Москва. 2009. 416с.

6. Assessing the role of nano-intellectual capital as a factor in the growth of high-tech industrial complex of Russia [Текст] / Odintsov, А.А. [и др.]// International JournalofAppliedBusinessand Economic Research. 2017. № 15. C.53-62. 